“(C) 2021 IEEE. Personal use of this material is permitted. Permission from IEEE must be obtained for all other uses, in any current or future media, including reprinting/republishing this material for advertising or promotional purposes, creating new collective works, for resale or redistribution to servers or lists, or reuse of any copyrighted component of this work in other works." 


\title{
Improving the Energy-Conversion Efficiency of a PV-TE System with an Intelligent Power-Track Switching Technique and Efficient Thermal-Management Scheme
}

\author{
Zhi-Hao Shen, Hao Ni, Can Ding, Member, IEEE, Guo-Rong Sui, Senior Member, IEEE, Hong-Zhi Jia, \\ Xiu-Min Gao, and Ning Wang, Member, IEEE
}

\begin{abstract}
A photovoltaic-thermoelectric (PV-TE) hybrid system can be used for efficient thermal energy utilization from the generated waste heat in PV device. In this paper, an efficient PV-TE hybrid System with intelligent power-track switching technique and thermal management based on energy conversion is proposed. To make the output power of PV-TE system stable and normalized, an incorporated stable-voltage circuit is designed based on energy conversion. In addition, a control-and-monitoring strategy is launched in the system to realize the normal collecting for the output power of PV-TE system. Finally, a battery protection circuit is performed to ensure that the energy converted by the entire system is effectively stored. The experimental results show that more electrical energy about 84034J was obtained with our energy harvesting system than that of a single photovoltaic cell. Besides, the thermal gradient of photovoltaic cells is indirectly reduced the operation of the whole system is automatically monitored due to the proposed intelligent power-track switching technique.
\end{abstract}

Index Terms-power-track switching technique, recycling thermoelectric conversion, energy harvesting.

\section{INTRODUCTION}

$\Delta \mathrm{t}^{\mathrm{t}}$ present, more than half of the world's energy A consumption is obtained from non-renewable energy sources, such as petrochemical fuels [1-3]. However, energy recovery from petrochemical fuels leads to considerable energy waste and pollution $[4,5]$. The sun is the main source of energy on the earth's surface, energy that can be retrieved in an environmentally friendly way, which is widely abundant, and is sustainable [6,7]. Therefore, solar energy has become a focus of study because of these advantages. Using solar photovoltaic cells and energy conversion allows light energy to be harvested and transformed to electrical energy. However, the

This work was supported by the NSFC from grant 61804096, the National Key Research and Development Plan-Earth Observation and Navigation Key Special Project from grant 2017YFB0503102, and the National Key Research and Development Program of China from grants 2018YFC1313803 and 2018YFA0701800. (Corresponding author: Ning Wang).

Z.-H. Shen, H. Ni, G.-R. Sui, H.-Z. Jia, X.-M. Gao, and N. Wang are with the Engineering Research Center of Optical Instrument and System, Ministry of Education, Shanghai Key Laboratory of Modern Optical System, University of Shanghai for Science and Technology, Shanghai 200093, China (e-mail: nwang@usst.edu.cn).

C. Ding is with the Global Big Data Technologies Center, University of Technology Sydney, Sydney, NSW 2007, Australia (e-mail: can.ding.1989@gmail.com). performance of a conventional solar photovoltaic cell is inversely proportional to its operating temperature due to the materials used in its construction and limitations in the manufacturing process $[8,9]$. This means a photovoltaic system faces serious heat-dissipation problems with working cell modules [10,11]. Many studies have focused on improving photovoltaic conversion using cooling devices. For example, the maximum efficiency of a photovoltaic (PV) panel in a concentrated photovoltaic system can be increased by about $17.8 \%$ using a water-immersion cooling technique, where the cell surface temperature can be made to lie within $31-39{ }^{\circ} \mathrm{C}$ [12]. Kuo et al. used cooling by circulated cold water to remove heat from photovoltaic cells. Their experimental results showed that using a water-circulation cooling system can improve the power capacity of a PV cell by $2 \%-15 \%$ and enhance the power-generation efficiency by $2.29 \%-3.37 \%$ [13]. Other cooling technologies, such as wind cooling [14], vapor-compression refrigeration [15], phase-change cooling [16], and thermoelectric cooling [17], have also been used in PV cell modules to improve photovoltaic conversion. In particular, the thermoelectric cooling technique reduces the surface temperature of a PV module considerably, since the technique produces no mechanical noise or pollution, and does not need continuous low-pressure conversion. However, Peltier cooling, needing for additional power, inevitably decreases the total efficiency of a PV system. Based on the similar device (thermoelectric cooler, TEC) structure, thermoelectric generator (TEG), the electric power can be generated from external heat sources via thermoelectric-energy harvesting and conversion, which is expected to improve the overall utilization rate of energy. The harvesting of electrical energy from thermal energy can be used as a kind of auxiliary cooling [18-21]. Wang et al. proved the principle of thermoelectric conversion using a thermal-reusing scheme in a TEG, where $5.38 \%$ of the waste heat was recovered [22]. Furthermore, a photovoltaic-thermoelectric (PV-TE) combination system was determined to be more promising in energy utilization than a single solar cell [23]. Rodrigo et al. [24] compared four designs of a TEG-concentrator PV hybrid module with that of a typical concentrator PV-only module. The global efficiency of the PV-TE system for a given set of conditions is enhanced by up to 4.75\% through experiment for the concentrator PV-TE structure. The yielded power generation per hour of 
photovoltaic capacity can be increased by up to $7.00 \%$ with hybridization. Using a miniaturized micro-scale thermoelectric generator $(\mu$-TEG), Yan et al. studied a MEMS-based thermoelectric-photoelectric integrated power generator, where the measured conversion efficiency reached $4.45 \%$ in a single silicon chip integrating the $\mu$-TEG and solar cell [25]. Preliminary theoretical and experimental work showed that this combined PV-TE system considerably improved energy-conversion efficiency; but this scheme did not involve power management and thermal-management techniques, such as power-stabilization conversion, monitoring, and protection.

In order to solve the above problem, an effective thermal-management scheme for a PV-TE system, employing an intelligent power-track switching technique, is proposed. To our knowledge, this is the first description of the heat released by a PV panel being recycled and used to produce a self-monitoring mechanism. The paper is organized as follows: Section II describes the principle of power generation with a PV panel and a TEG. Section III presents the design flow of the proposed self-monitoring PV-TE system. In Section IV, the performance of the proposed system is evaluated. Finally, Section V presents the conclusions.

\section{PRINCIPLE OF POWER GENERATION}

In our design, a combination of a photovoltaic cell and TEG is used to form an energy-conversion unit, the aim of which is to obtain maximal energy from light and heat using the existing energy-conversion devices. Two devices, including a PV solar cell and TEG, are employed to harvest electrical energy.

\section{A. Photovoltaic Cell}

Fig. 1 shows the structure and equivalent-circuit diagram of a typical photovoltaic solar cell. As illustrated in Fig. 1(a), the structure of a PV panel comprises a concentrator, EVA (ethylene vinyl acetate copolymer), a p-n junction, and Tedlar. In addition to protecting the whole power conversion system,

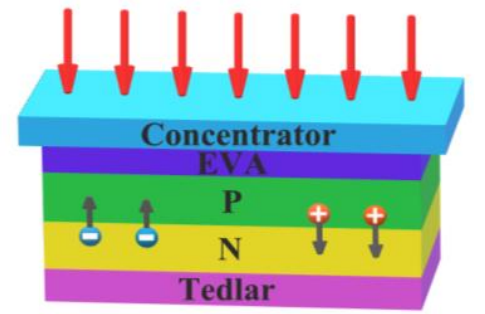

(a)

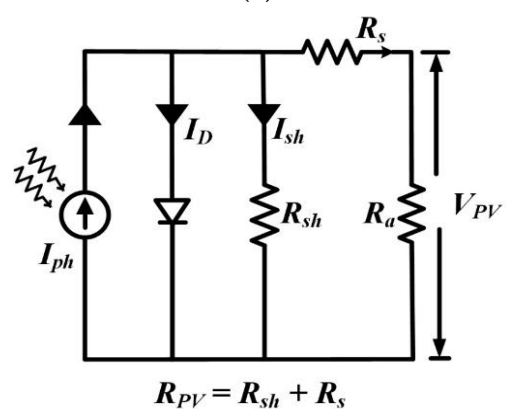

(b)

Fig. 1. (a) Schematic diagram of photovoltaic solar cell. (b) Equivalent-circuit diagram of solar cell. the role of the EVA is to fix the toughened glass of the PV panel and the main body of power generation. Also, the Tedlar protects and supports the cells with its properties of electrical insulation, water resistance, and resistance to aging, which is located on the back of the solar panel. It is a solar cell that converts light energy to electrical energy directly through the photoelectric effect or the photochemical effect. When exposed to sufficient light, PV panels convert solar radiation to electricity. An equivalent-circuit diagram of photovoltaic cells is shown in Fig. 1(b). When the p-n junction absorbs solar radiation, it produces an output current $I_{p h}$ via the photovoltaic effect. In the actual photovoltaic cell working condition, a diode current $I_{D}$ can be used to represent the internal current. When the electrical energy is produced in photovoltaic cell , energy losses inevitably occur when the internal current flows. These losses are represented by a resistance $R_{s}$, in series in the equivalent circuit. Taking into account internal defects of the electrodes and other factors during the actual application process, the current that should pass through the load $R_{a}$ is short-circuited. This is equivalently expressed by a parallel resistance $R_{s h}$. In summary, due to specific factors, such as material characteristics and manufacturing processes, $100 \%$ of solar radiation cannot be absorbed by PV panels. Only a proportion of radiation is absorbed and converted. The power absorbed from the sun can be described as:

$$
P_{a b s}=C G \tau \alpha A_{P V}
$$

where $C$ and $G$ are the concentration ratio and solar radiation, and $\tau$ and $\alpha$ are the transmissivity and absorptivity, respectively. $A_{P V}$ is the photosensitive area of PV cells. The photovoltaic cell absorbs the light energy and converts it to electrical energy, but the conversion efficiency has an inverse relationship with the working temperature of the device. Combining the equivalent-circuit diagram with photovoltaic effect, for a given set of external environmental change factors, the resistances $R_{s}$ and $R_{s h}$ increase significantly when the temperature of device increases, while the output voltage of the load $V_{p v}$ decreases. Equation (2) gives the relationship between PV panel conversion efficiency and its temperature [26]:

$$
\eta=\eta_{\text {ref }}\left[1-\theta\left(T_{P V}-T_{\text {ref }}\right)\right]
$$

where $\eta_{r e f}$ is the cell efficiency at $T_{r e f}=298 \mathrm{~K}, \theta$ is the temperature coefficient of solar-cell efficiency, and $T_{P V}$ is the current temperature of the photovoltaic panel. The solar-cell output power $P_{\mathrm{PV}}$ is obtained by multiplying Eqs. (1) and (2). Then, the solar-cell output power controlled by the working temperature can be expressed by:

$$
\begin{aligned}
& P_{P V}=P_{a b s} \times \eta \times \frac{R_{a}}{R_{P V}+R_{a}} \\
& =P_{a b s} \times \eta_{r e f}\left[1-\theta\left(T_{P V}-T_{r e f}\right)\right] \times \frac{R_{a}}{R_{P V}+R_{a}}
\end{aligned}
$$

Equation (3) represents the total output power of the photovoltaic cell, which is directly proportional to the cell's conversion efficiency; its conversion efficiency is inversely proportional to solar-cell temperature. In conclusion, the lower 
the temperature of the PV panels, the higher the power output.

\section{B. Collaborative Electrothermal Cooling}

Fig. 2(a) shows a typical single-stage TEG, consisting of an array of TE (thermoelectric) legs sandwiched between two thermally conducting but electrically insulating ceramic plates. The Seebeck effect involves movement of the carriers in the conductor from the hot end to the cold end under a temperature gradient, with an accumulation of carriers at the cold end. This forms a potential difference inside the material, and at the same time, the reverse influence to energy conversion is generated because of the potential difference. When the thermally moving charge flow and the internal electric field reach a dynamic balance, a stable thermoelectromotive force is formed at both ends of the semiconductor. Fig. 2(b) shows the equivalent-circuit diagram of the TEG. An electric current $I_{T E}$ is generated when a thermal gradient is in place, end-to-end in the thermoelectric generator. Due to defects in the manufacturing process and the resistance characteristics of the material itself, the transformed energy will be further shunted. This is expressed as $R_{s h}$ in the equivalent-circuit diagram, which equals the internal resistance of the TEG.

According to the Seebeck effect, when there is a temperature difference between the two ends of the TEG, the thermos-electromotive will be induced across the thermocouples, which can be expressed by:

$$
V_{O C}=S \times\left(T_{h}-T_{c}\right)
$$

where $V_{o c}$ is the Seebeck electromotive force, $T_{h}$ and $T_{c}$ are the temperatures of the two ends of the TEG, and $S$ is the Seebeck coefficient of the module. Therefore, the load voltage in the circuit can be described as:

$$
V_{T E}=\frac{V_{O C}}{R_{T E}+R_{b}} \times R_{b}
$$

where $R_{T E}$ and $R_{b}$ are the resistance of the TEG and the load in the circuit, respectively. The output power of the TEG can then be given by:

$$
P_{T E}=\frac{\left(V_{b}\right)^{2}}{R_{b}}=\left[\frac{S\left(T_{h}-T_{c}\right)}{R_{T E}+R_{b}}\right]^{2} \times R_{b}
$$

When the TEG is operating, the greater the temperature difference between hot side and cold side of the external environment, the greater the voltage $V_{T E}$ at the output terminal, and the greater the output power $P_{T E}$.

\section{Energy Efficiency of the Total System}

Using the above equation, the current energy-conversion status of the photovoltaic thermoelectric system can be obtained. The effective use of solar energy is a practical problem because the sun's lighting conditions change dynamically throughout the day. Therefore, the energy converted in a day is obtained by solving the integral of the conversion efficiency.

The solar radiation absorbed by the PV cell over a period of time can be expressed as:

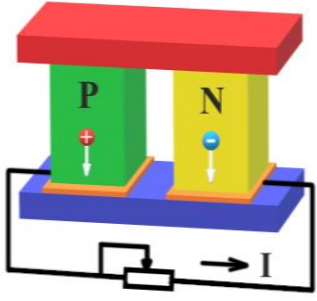

(a)

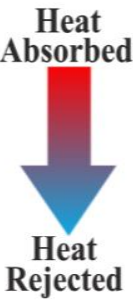

Fig. 2. (a) Schematic diagram of single-stage TEG cell. (b) Equivalent-circuit diagram of TEG.

$$
E_{a b s}=\int_{0}^{t} C G(t) \tau \alpha A_{P V} d t
$$

where $G(t)$ represents the change in solar-radiation intensity as a function of time. The meaning of the other symbols is given previously. Therefore, the total converted energy can be expressed by:

$$
\begin{aligned}
& E_{c o n}=E_{P V}+E_{T E} \\
& =\int_{0}^{t} P_{P V} d t+\int_{0}^{t} P_{T E} d t \\
& =\int_{0}^{t} \frac{P_{a b s}(t) \times \eta(t) \times R_{a}}{R_{P V}+R_{a}} d t+\int_{0}^{t}\left[\frac{s \times\left[T_{h}(t)-T_{c}(t)\right]}{R_{T E}+R_{b}}\right]^{2} \times R_{b} d t
\end{aligned}
$$

where $P_{a b s}(t)$ and $\eta(t)$ are the absorbed power and conversion efficiency of the PV cells as functions of time. $T_{h}(t)$ and $T_{c}(t)$ are the temperatures of both sides of the TEG as functions of time. The other elements are identified as ideal state, i.e., they are constants. Therefore, the total energy efficiency is the ratio of the total energy converted to the total energy absorbed, which can be expressed by:

$$
\begin{aligned}
& a=\int_{0}^{t} \frac{P_{a b s}(t) \times \eta(t) \times R_{a}}{R_{P V}+R_{a}} d t \\
& b=\int_{0}^{t}\left[\frac{S \times\left[T_{h}(t)-T_{c}(t)\right]}{R_{T E}+R_{b}}\right]^{2} \times R_{b} d t \\
& c=\int_{0}^{t} C G(t) \tau \alpha A_{P V} d t \\
& \eta_{\text {overall }}=\frac{E_{\text {con }}}{E_{\text {abs }}} \times 100 \%=\frac{a+b}{c} \times 100 \%
\end{aligned}
$$

Equation (9) shows that, on the one hand, in order to improve the overall conversion efficiency, the heat sink of the photovoltaic cell can be strengthened to increase the output power. On the other hand, the energy efficiency can be improved by increasing the temperature difference between the two ends of the TEG. In this article, the two issues including intelligent power-track switching technique and effective thermal-management scheme are combined to form a PV-TE system, and the overall conversion efficiency is improved by using the TEG to recover the thermal energy in the photovoltaic cell. At the same time, a sensor is driven by the electrical energy converted from the heat energy to monitor output performance, therefore the energy utilization rate is improved. 


\section{ENERgy Management AND System Design OPERATING MECHANISM}

Although the PV-TE hybrid has been implemented before, the research still has room for further improvement. For example, the performance analysis of the PV-TE system only stays at the theoretical simulation level in other research work [27-28]. Similar research [29-30] only uses the existing experimental equipment to measure the output of the PV-TE system to achieve improvement, but this part of the energy in the actual application process cannot effectively prove the improvement of the system's energy utilization rate. In this work, the PV-TE system can work at lower temperature because of the control/monitoring/stabilizing circuits. Some modules can be powered by the electric energy obtained by the thermoelectric conversion principle, and the electric energy output of the whole system can be monitored, so as to realize the effect of waste heat recovery and reuse. Fig. 3 shows a schematic diagram of thermal-management system that realizes further utilization of heat energy and improves the energy efficiency of PV cells. The thermal-management system uses an intelligent power-track switching technique. With this technique, the harvested energy is used to drive sensors and charge the $5 \mathrm{~V}$ battery pack at the same time, exhibiting a stable voltage output. By switching between self-checking and charging modes, an efficient control and monitoring strategy is obtained to enhance energy conversion and harvesting. A battery-protection circuit is designed and optimized to prevent battery damage.

\section{A. Compensation network current loop stable voltage design using average current mode modulation}

The PV cells absorb light energy from the sun, converting it to electrical energy, but the brightness of the sun varies dynamically throughout the day, affecting cell performance. In addition, the rising working temperature of photovoltaic cells will lead to the increasing internal resistance of photovoltaic cells, which indirectly reduces the effective output of photovoltaic cells. Therefore, the process of energy conversion from two power sources including photovoltaic cell and TEG is affected by the surrounding environment as well. However, the power transformed by PV is mainly depended on the intensity of radiation. On one side, the radiation intensity of solar energy is always in a state of dynamic change in a day due to the change of meteorological environment. As a result, the PV voltage also changes dynamically, and can reach a maximum, especially at noon. On the other side, because the energy conversion efficiency cannot reach $100 \%$, the solar radiation absorbed by photovoltaic cells also cannot be completely converted into electrical energy for output. In the end, the energy that has not been converted into electricity will be remained in the photovoltaic cells in the form of heat energy. Due to the Seebeck effect, this unused thermal energy can be converted to electricity by TEGs. However, the direct output power of the PV-TE system is not stable, making the system unsuitable for electrical applications. In order to obtain a

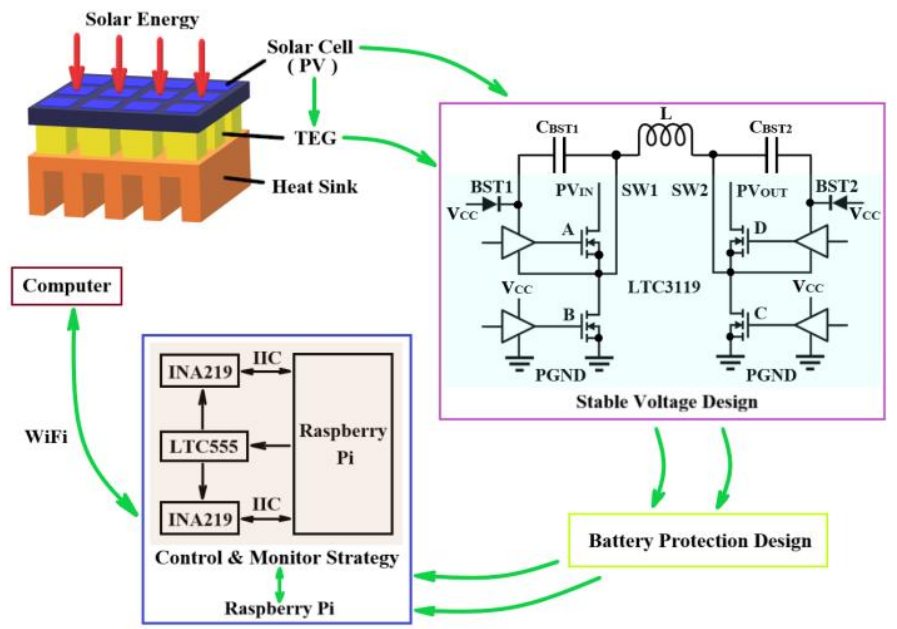

Fig. 3. Proposed thermal-management with intelligent power-track switching technique and automatic self-monitoring mechanism.

stabilized electrical energy output, DC-DC modules are employed.

However, the electromotive force generated by TEGs is much smaller than that of solar cells. It is impossible to obtain two difference voltages synchronously using one DC-DC module. Consequently, the process of DC-DC conversion should be done separately. In our design, two DC-DC modules with models of LTC3119 and LTC3109 are used to produce a stable voltage-conversion circuit based on the principle of positive-feedback amplification, where output voltages of $12 \mathrm{~V}$ and $5 \mathrm{~V}$ are obtained, respectively. Considering the necessity of the application of voltage stabilizing circuit, this design refers to the low power consumption voltage stabilizing circuit [31], and designed compensation network current loop stable voltage design using average current mode modulation. Fig. 4 shows a diagram of the design, the PCB, and the test result. The internal current mode control loop error amplifier compares the sensed average inductor current and the commanded average inductor current to modulate the SW1 and SW2 pins on a cycle-by-cycle basis. Average current mode control is similar to peak current mode control, except that the average current amplifier, by virtue of its configuration as an integrator, controls the average current instead of the peak current. This difference eliminates the peak-to-average current error of peak current mode control, while maintaining most of its inherent advantages. Compensation of the inner current loop is accomplished by an internal compensation network that is optimized to provide a high bandwidth and low regulation error under all situations. As shown in Fig. 4(c), the input power can be converted to an ideal voltage value. The output power of PV cells is stable at 12 $\mathrm{V}$, and the output power of TEGs is stable at $5 \mathrm{~V}$. In the experiment, with the help of the boost module, the converted energy can be transmitted to one energy storage module at a stable voltage value. This avoids the occurrence of undervoltage or overvoltage damage to the load circuit system.

\section{B. Control and Monitoring Strategy}

The commonly used output power monitoring module only uses the single-chip microcomputer to interconnect with the sensor to read performance data [32]. In this design, based on 

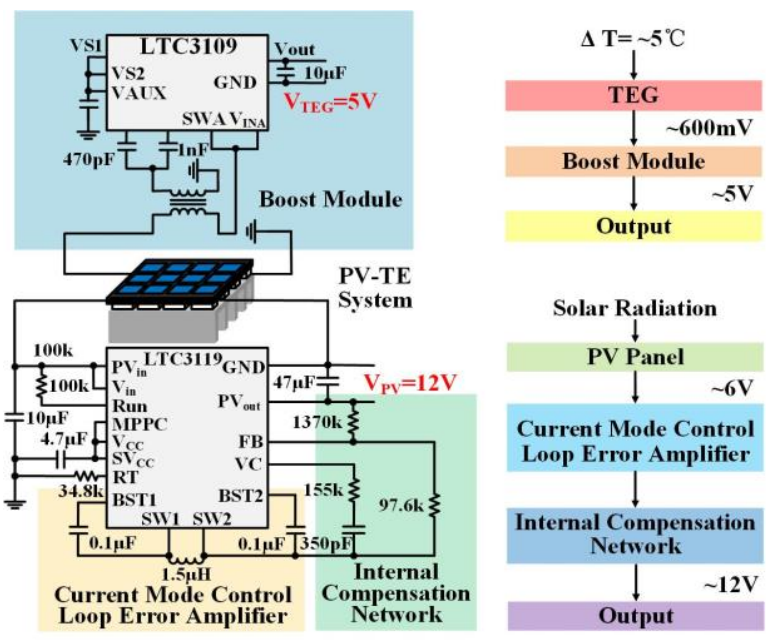

(a)

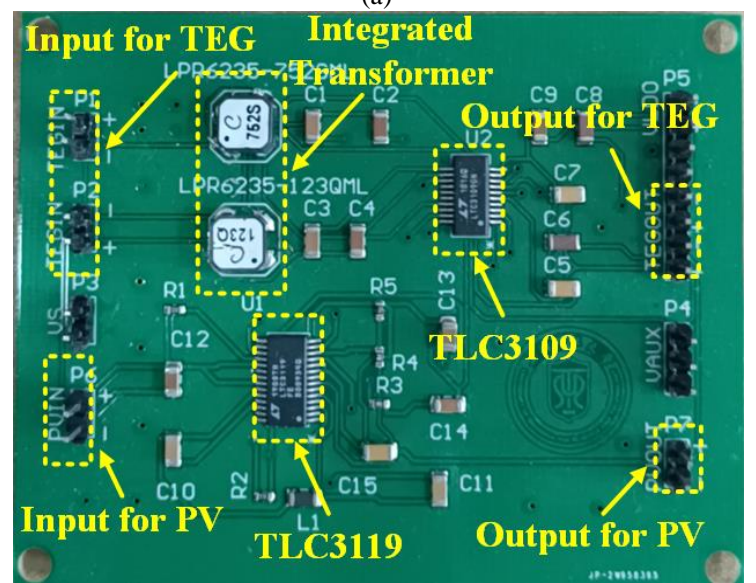

(b)

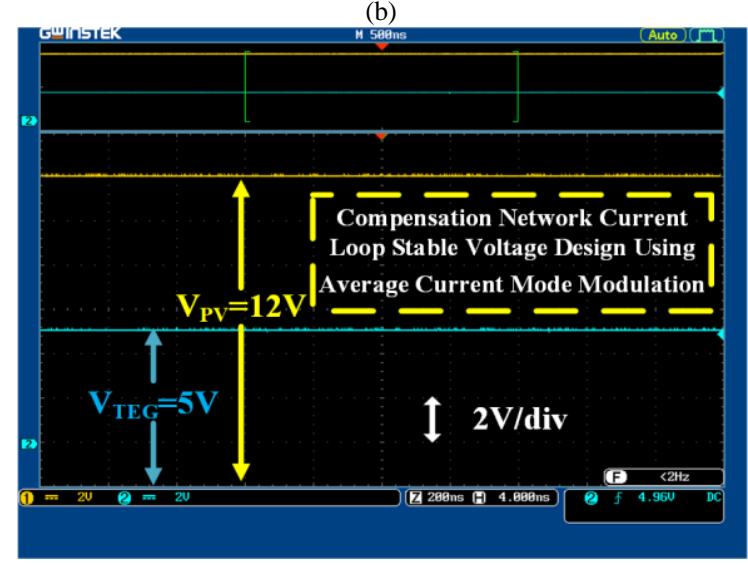

(c)

Fig. 4. Compensation network current loop stable voltage design using average current mode modulation. (a) Schematic diagram. (b) PCB circuit. (c) Measurement results.

the trigger extension, the intelligent power rail switching technology is proposed and applied to the system design, further realizing the demand for improving energy efficiency. In our proposed thermal-management system, the output power with a voltage of $12 \mathrm{~V}$, which is converted by PV cells, was supplied to the charging battery pack; while the electricity with a $5 \mathrm{~V}$ electromotive force generated by TEGs was supplied to the control and monitoring system, as shown in Fig. 5. For the control and monitoring strategy, an intelligent power-track switching technique was integrated into the control module to control the direction of current generated by TEGs. When the control module was powered on, the monitoring system was activated to self-check the charging status of the whole PV-TE system, including the $12 \mathrm{~V}$ and $5 \mathrm{~V}$ battery packs. Once the control module was powered off, the current was transferred to the battery pack at $5 \mathrm{~V}$ to achieve energy storage. Due to this control and monitoring strategy, the electricity generated by the efficient thermal-management mechanism was further utilized without additional energy expenditure. To achieve high-precision timing and measurement, two chips with models of TLC555 and INA219 were integrated into the control and monitoring module circuit. In this system, an intelligent current management strategy was built based on the principle of an

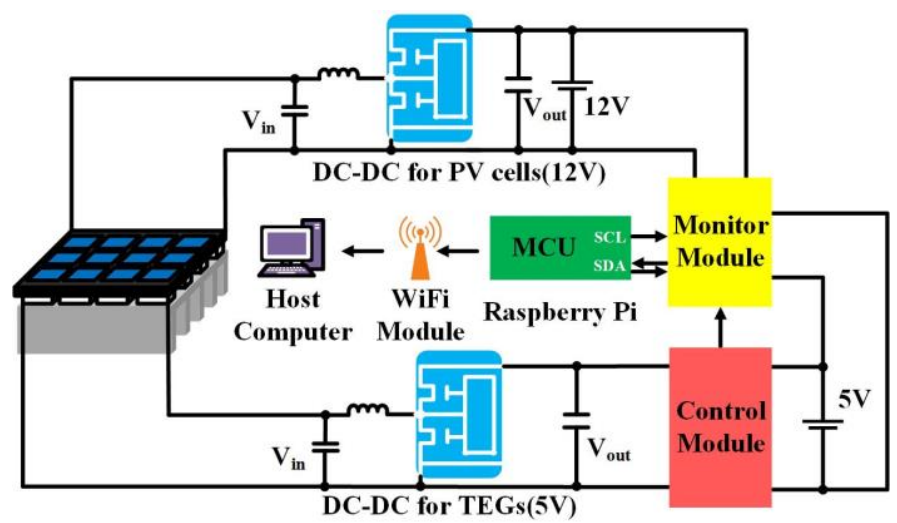

Fig. 5. Control and monitoring strategy.

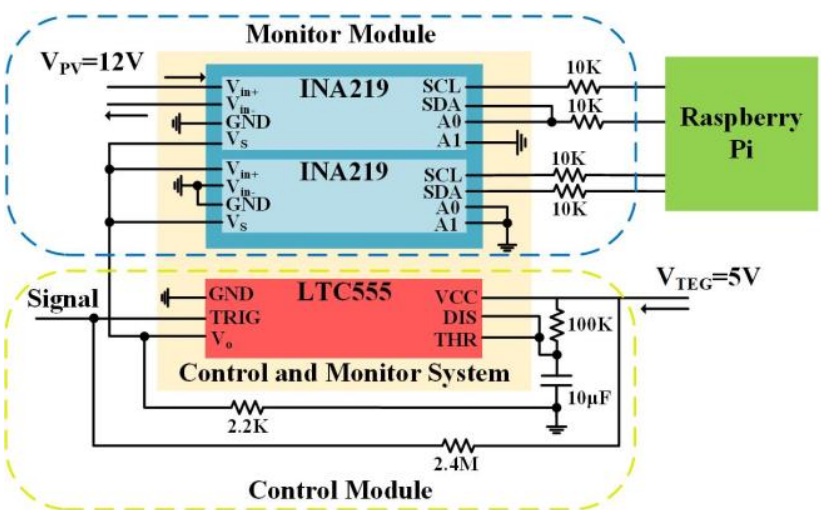

Control and Monitor Strategy

(a)

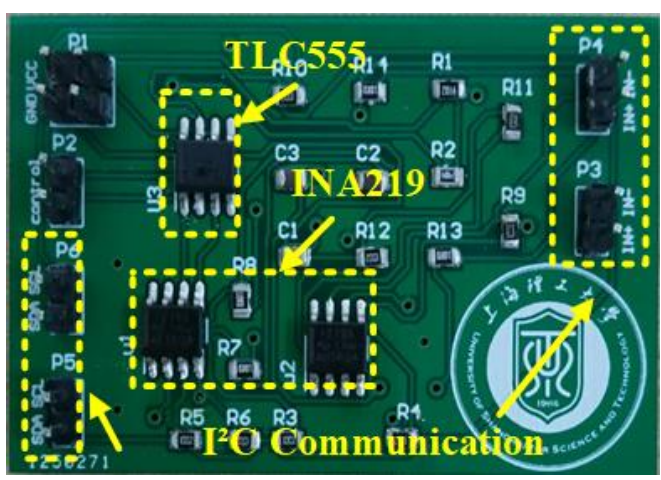

(b)

Fig. 6. (a) Schematic diagram of control and monitoring module. (b) PCB of control and monitoring strategy. 
RC-delay circuit, combined with a TLC555 chip and external circuit. The driving time of the monitoring module could be reset by changing the value of the resistance and capacitance in the external circuit. In our design, the monitoring module was driven every 5 minutes to read the output power from both the PV cells and TEGs. The core part of the monitoring module contained two INA219 chips, which could be used to read the relevant information through the $\mathrm{I}^{2} \mathrm{C}$ communication protocol. The physical $\mathrm{I}^{2} \mathrm{C}$ interface consists of two wires, which are the serial clock (SCL) and serial data (SDA), respectively. Both SDA and SCL lines have an open drain or collector drive with an input buffer that supports bidirectional communications or data transfer. In addition, they must be connected to VCC through a pull-up resistor [33]. A Raspberry Pi read the power output data from the SDA by sending a $400 \mathrm{kHz}$ clock signal to the SCL port of the monitoring module, and configuring relevant registers through the SDA port according to the $\mathrm{I}^{2} \mathrm{C}$ communication protocol. A single-chip microcomputer, namely Raspberry Pi, was used to establish communication with monitoring module, and to transmit data to the host computer through the onboard WiFi module. The specific circuit design of control and monitoring strategy is shown in Fig. 6. The design of monitoring and control circuit includes two advantages. On one hand, the problem of reading the output power data of entire system can be solved with the implement of monitor strategy. On the other hand, the driving power monitoring chip (INA219) without disconnecting the energy storage module control circuit can also be realized during the electric energy transmission process.

Since the energy of the entire control and monitoring module is fully supplied by TEGs, the energy conversion efficiency can be enhanced with our proposed thermal management. With the help of the intelligent power-track switching technique, the monitoring module and battery pack do not require extra power. Therefore, this heat recovery mechanism provides the power of the intelligent self-detection circuit, resulting in decreased operation costs. Therefore, the control and monitoring strategy improves the overall energy utilization rate and reduces energy waste. Furthermore, the core competitiveness and practical application value of the design has been enhanced.

\section{Battery Protection Design}

Inside the lithium battery, overcharging, deep discharging, and a large current seriously impact the performance and service life of the whole system. Under these conditions, a large amount of gas is generated in the battery, resulting in a rapid increase in internal pressure, easily leading to explosions and other safety problems. Therefore, a protection circuit for effectively monitoring the battery's charge and discharge status is needed for all lithium batteries. This circuit prevents damage to the battery, even turning off the charge and discharge circuit under certain conditions. In this design, a battery protection module is designed using MOSFET switch technology [34].

In our work, both the R4502 chip and the SC8205 chip are integrated in one PCB to protect the lithium battery as shown in Fig. 7. The protection circuit consists of two MOSFETs
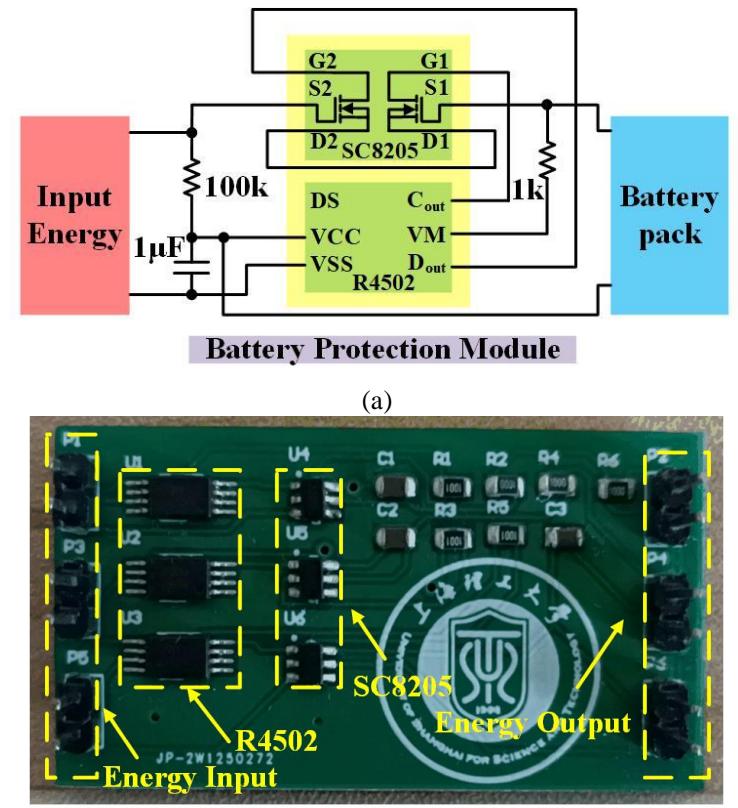

(b)

Fig. 7. (a) Schematic diagram of battery protection module. (b) PCB of battery protection module.
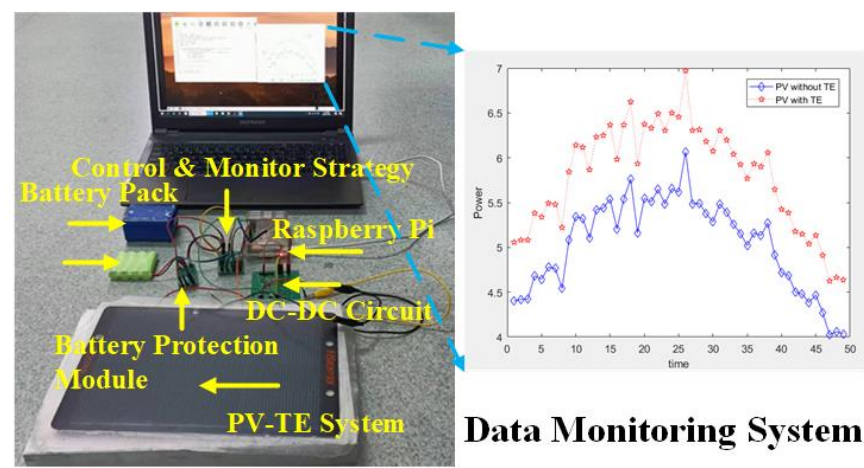

Data Monitoring System

(a)

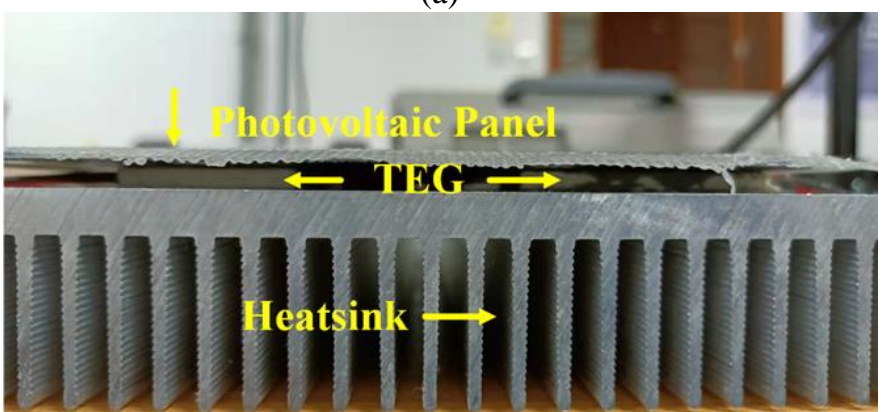

(b)

Fig. 8. Experimental equipment diagram (a) Demonstration of the double power-supplying system employing power-track switching technique for driving sensors and charging battery pack with $5 \mathrm{~V}$. (b) Side-view image of the double power-supplying system with PV, TEG, and heat sink.

(SC8205), a control IC (R4502), and various other components. The control IC is responsible for monitoring the battery voltage and loop current, and controlling the gates of the two MOSFETs. The MOSFETs act as switches in the circuit and control the turn-on and turn-off of the charging circuit and the discharging circuit, respectively. In the normal state, the "C $\mathrm{Cout}_{\text {ot }}$ 
and " $\mathrm{D}_{\text {out }}$ " pins of R4502 chip in the circuit have a high output voltage - both MOSFETs are in the conducting state, and the battery can be charged and discharged freely. Because the on-resistance of a MOSFET is very small, usually less than 30 milliohms, its on-resistance has little effect on the performance of the circuit.

During charging of the lithium battery pack, if the charger circuit loses control, the battery voltage will continue to keep charging with constant current after the battery voltage exceeds $4.2 \mathrm{~V}$. At this time, the battery voltage continues to rise. Once the battery voltage exceeds $4.2 \mathrm{~V}$, the battery chemical side reaction will be aggravated, causing battery damage or safety issues. In a battery with a protection circuit, when the control IC detects the battery voltage reaching $4.2 \mathrm{~V}$, its " $\mathrm{C}_{\text {out }}$ " pin changes from high voltage to zero voltage. This turns the MOSFETs from on to off, thereby cutting off the charging circuit, so that the charger can no longer charge the battery, and thus ensuring overcharge protection. During discharge of the lithium battery pack to an external load, the battery pack voltage gradually decreases. Given that the battery voltage drops to $3.7 \mathrm{~V}$, the battery pack capacity has been completely discharged or even over-discharged. At this time, if the battery continues to discharge the load, the battery becomes permanently damaged. As soon as the control IC detects that the battery voltage is lower than $3.7 \mathrm{~V}$ during the battery discharge process, it will change its " $\mathrm{D}_{\text {out }}$ pin from high voltage to zero voltage. MOSFETs are then turned off, cutting off the discharge circuit, so that the battery can no longer discharge the load, and ensuring over-discharge protection. With the addition of a battery protection module, the operation of the energy-storage module is more intelligent and automatic. While protecting the energy-storage module, this battery protection design also reduces unnecessary financial investment in system operation, and enhances the potential of the module in practical applications.

\section{RESULTS AND DisCUSSION}

\section{A. Test Setup and Environment}

The experimental equipment is shown in Fig. 8. The hybrid energy generator is composed of one PV panel (MYG6W08) and four TEGs (TEG-450-1.8-1.0). The PV-TE system module is resting on the heat-sink surface which has enough fins with ambient air flowing to ensure the heat dissipation. Due to the addition of TEG, there is a certain gap between the photovoltaic cells and the heat sink in the whole system, which can also promote the air flowing to achieve the effect of auxiliary cooling. The temperature of key points is recorded by a thermometer (HT-9815). Environmental factors significantly influence the performance of the hybrid energy generator, producing an unstable output. To mitigate this problem, a compensation network current loop stable voltage design using average current mode modulation is introduced; this is composed of two voltage regulators (LTC3119 and LTC3109), resistors $(34.8 \mathrm{k} \Omega, 97.6 \mathrm{k} \Omega, 100 \mathrm{k} \Omega, 155 \mathrm{k} \Omega, 1370 \mathrm{k} \Omega$ ), an inductor $(0.1 \mu \mathrm{H})$, capacitors $(350 \mathrm{pF}, 0.1 \mu \mathrm{F}, 1 \mu \mathrm{F}, 2.2 \mu \mathrm{F}, 10$ $\mu \mathrm{F}, 220 \mu \mathrm{F}, 1 \mathrm{nF}, 4.7 \mathrm{nF}, 0805$ package), and two transformers (LPR6235-752SML and 123QML). Energy originates in two ways: one way in which the photovoltaic panel is output to a lithium battery pack with a voltage of $12 \mathrm{~V}$; and another way in which the TEGs are output to the control and monitoring

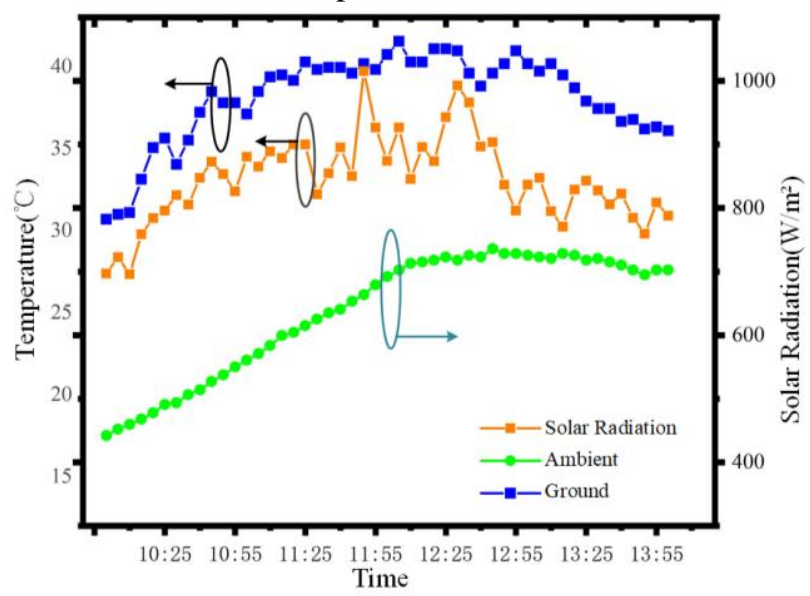

Fig. 9. Environmental data that mainly affect the results of the experiment.

module with a voltage of $5 \mathrm{~V}$. The control and monitoring strategy circuit is integrated with one timer chip (TLC555), two power monitor chips (INA219), resistors $(2.2 \mathrm{k} \Omega, 10 \mathrm{k} \Omega, 100$ $\mathrm{k} \Omega, 2.4 \mathrm{M} \Omega, 0805$ package), and capacitors $(10 \mu \mathrm{F}, 0805$ package). When the energy output

needs to be read, the INA219 is driven to read the system output data using the intelligent power-track switching technique. In other cases, the energy will be transferred and stored in the lithium battery pack with a voltage of $5 \mathrm{~V}$. Finally, a battery protection module composed of a control IC (R4502), MOSFET chip (SC8205), resistors $(1 \mathrm{k} \Omega, 100 \mathrm{k} \Omega, 0805$ package), and capacitors $(10 \mu \mathrm{F})$ is designed to prevent overcharge and over discharge. Fig. 9 shows the environmental data that mainly affect the results of the experiment from 10:00 am to 2:00 $\mathrm{pm}$. Here, the ground temperature refers to the temperature of the ground on which the PV-TE system is placed. The monitoring data show that the light intensity and environmental temperature in this period are the strongest in one day, so the relevant test results are representative, which improves the credibility of the experimental results.

\section{B. Temperature Test}

The temperature of each key point in the operation of the PV-TE system and single PV cell is shown in Fig. 10. $T_{P V}$ with TE is the temperature of the top surface of the solar cell, $T_{P V}$ without TE is the temperature of the single PV panel without TE devices, $T_{T H}$ is the temperature between the bottom side of PV panel and the hot side of the TEG, and $T_{T C}$ is the temperature between the cold side of TEG and the heatsink. The surface temperature $T_{P V}$ without TE (of the solar cell in the PV-only system) is always higher than that of the solar cell in the PV-TE system. This is mainly due to the presence of the TEG, conducive to heat transfer and utilization. $T_{P V}$ is close to $T_{T H}$ in the early stage of the experiment. However, $T_{P V}$ is significantly greater than $T_{T H}$ after the time of 11:40. From a theoretical point of view, due to the addition of TEG, a sufficient gap is created between the solar cell and the heat sink, so the increase in the convection coefficient will also cause the average temperature of the PV-TE system to be higher than that 
of a single photovoltaic cell. This can be attributed to TEGs effectively extracting heat from the absorbed solar energy in the

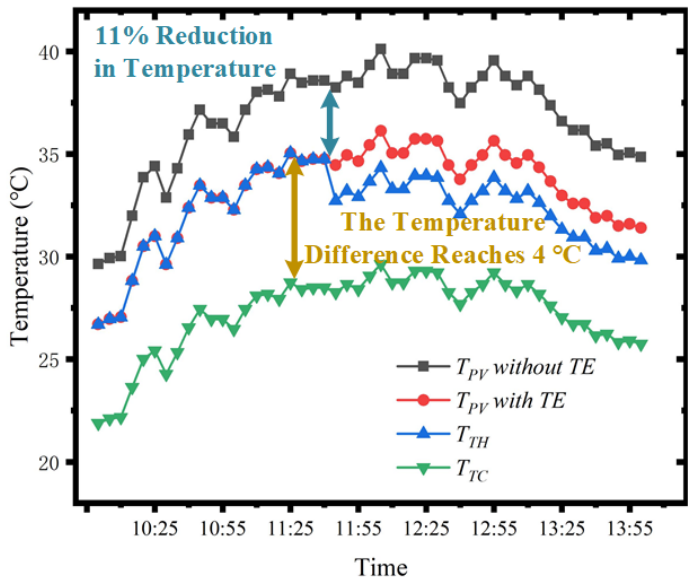

Fig. 10. Temperature change around noon for different test points in PV-TE experiment systems.

PV panel at the beginning of the experiment. As the PV panel continues to operate with increasing ambient temperature, a great deal of heat accumulates in the PV panel. As a result, the TEGs cannot remove all the heat from the PV panel. Finally, significant differences appear between the data for $\mathrm{T}_{\mathrm{PV}}$ and $\mathrm{T}_{\mathrm{TH}}$. Using the temperature difference between the upper and lower surfaces of the TEG, a proportion of the heat energy is exported from the photovoltaic cell. Another proportion of this heat energy is converted to electrical energy based on the Seebeck effect, and the remaining proportion is exported downward through the heat-sink. Compared with the system that has only heat-sink-assisted heat dissipation, the temperature in our proposed PV-TE system can be decreased by an average of $11 \%$ - the system is cooled by an average of $3-4^{\circ} \mathrm{C}$, from $33^{\circ} \mathrm{C}$ to $28^{\circ} \mathrm{C}$ during the experimental test. Experimental results show that the PV-TE system has obvious advantages in terms of output power compared with the single PV panel. This is mainly because the temperature of the PV panel in the PV-TE system is lower than that of single photovoltaic panel, and the output performance of the photovoltaic panel is inversely proportional to its temperature.

\section{Output Power}

Fig. 11 is an output power comparison between the PV with TE (PV-TE) and PV without TE schemes. From the beginning up to just before 12:05 noon, the output powers of both the PV without TE and PV-TE systems are in proportion with the solar radiation intensity. The temperatures of the working devices of PV and TE gradually increase with increasing environmental temperature and solar radiation intensity. However, output power begins to decrease, even when the temperature reaches its maximum at the time of 12.25 . This is because the conversion performance of the photovoltaic module is inversely proportional to its temperature. Then, output power drops significantly because the temperature of the photovoltaic panel is still kept at a relatively high stage, where the conversion efficiency decreases, especially at 12:55. Moreover, the photovoltaic output power in the PV-TE system is obviously greater than that of a single photovoltaic panel system without TE. Since the temperature of the photovoltaic panel in the PV-TE system is always lower than that of a single

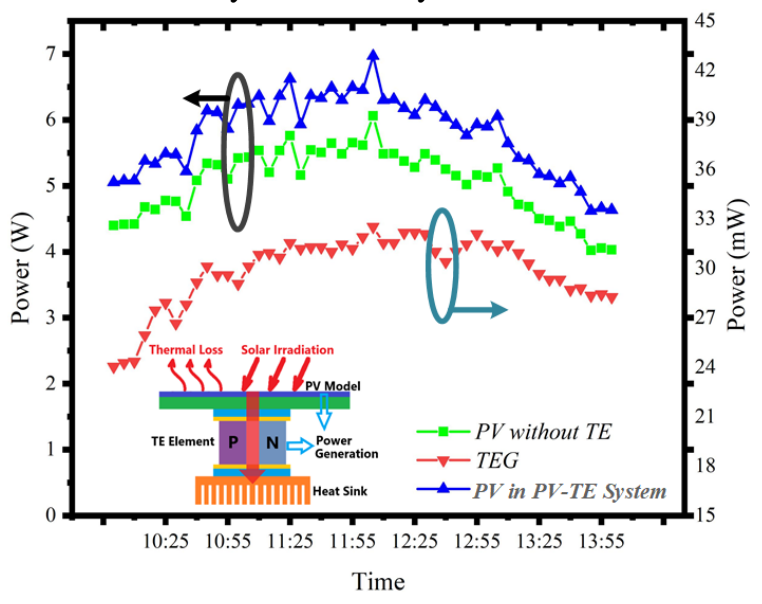

Fig. 11. Output power comparison.

photovoltaic cell system, the output effect of this solution is also better in terms of output power, which is increased by $13 \%$ from $5.54 \mathrm{~W}$ to $6.23 \mathrm{~W}$, on average.

This power enhancement is mainly due to the TEG, which reuses the thermal energy from the temperature gradient. In this experiment, a booster module is used to boost the voltage to a uniform value which can be outputted to drive the following circuits including control and monitoring strategy and battery protection design. With our proposed system, the electrical energy converted by the photovoltaic cell is boosted and kept stable at $12 \mathrm{~V}$, before it is transmitted to the lithium battery pack. Since the electrical energies produced by the PV and TEG differ by an order of magnitude, as shown in Fig. 11, the electrical energy produced by the TEG is boosted to $5 \mathrm{~V}$ using the other independent DC-DC module, while driving the power sensor and charging the $5 \mathrm{~V}$ battery pack. The control model, which uses the integrated intelligent power-track switching technique, enables the electric energy converted from TEG to determine whether to drive the monitoring module or charge the battery pack. After the power sensor is successfully driven by the energy generated by TEGs, the entire energy-conversion system is monitored. Then, the obtained information, including the power outputs of the single PV panel, PV panel in the PV-TE system, and TEGs in the PV-TE system, are transmitted to the Raspberry Pi and personal computer via WiFi.

The experimental results show that our proposed PV-TE system can operate at an output power larger than $6.5 \mathrm{~W}$ with the stored electrical energy using two power sources in a high-energy-intensity window. As a result, the energy-conversion efficiency of our system contributed by the TEG is improved compared with the PV system without TE.

\section{Energy-Conversion Efficiency}

In addition to output power, energy-conversion efficiency is also regarded as an important performance index in energy-conversion systems, as shown in Figs. 12 and 13. In Fig. 12 , the conversion efficiencies of the two schemes are compared. The PV-TE system generates more power than the single PV panel, thanks to its lower working temperature and high heat utilization. A numerical comparison of temperature difference and conversion efficiency improvement is shown in 
Fig. 13, where the data reflect the device temperature difference

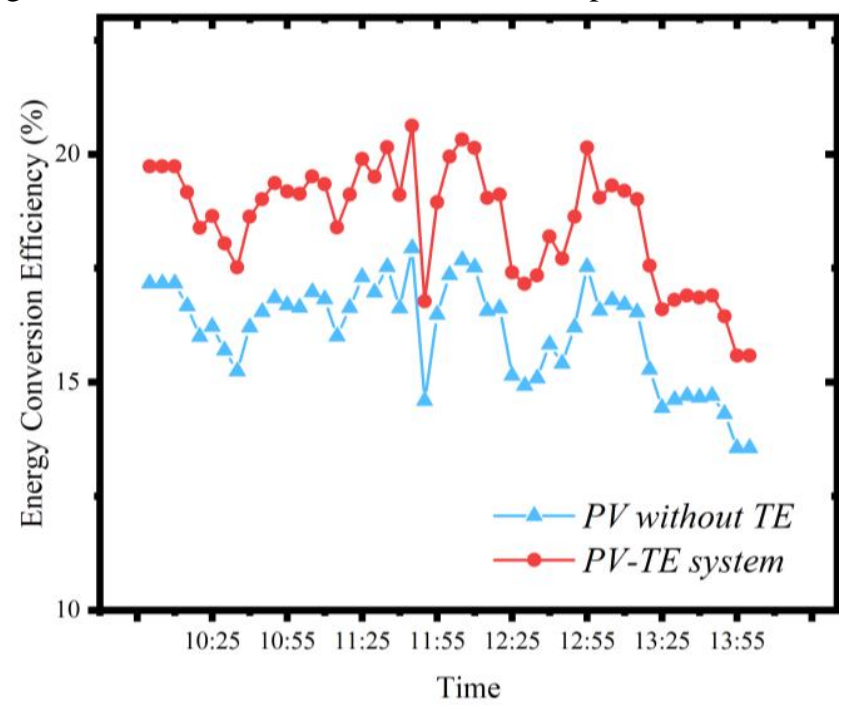

Fig. 12. Conversion efficiency comparison.

between the two schemes. In the initial stage of the experiment, the temperature difference gradually increases, and after a period of time, gradually decreases. The reason for this is that the PV panels begin to absorb solar energy at the same time in the early stage of the experiment. As shown in the Fig. 13, each column represents how much energy the PV-TE system and PV cell output in each 5 minutes. Obviously, the energy output of a photovoltaic cell system with a TEG structure is always higher than that of a single photovoltaic cell. According to statistics, the energy conversion system using the PV-TE system in the entire experiment obtained 84034J more electrical energy than a single photovoltaic cell and stored in the energy harvesting system.

However, because of the TEG, the PV-TE system eventually reaches equilibrium, since it has a stronger heat dissipation capacity than a single PV panel. Thanks to a gradual increase in ambient temperature and ground temperature, the performance of TEG decreases, and the temperature difference between the PV-TE system and single photovoltaic panel gradually narrows. In addition, solar radiation greatly influences the performance of the device. Therefore, the conversion efficiency of the PV panel decreases due to the relatively high temperature of the device and low radiation intensity at 12:55. At this time, due to the TEG, the solar energy is further used by TEG, which increases the improvement rate in conversion efficiency. The experimental results show that the conversion efficiency is

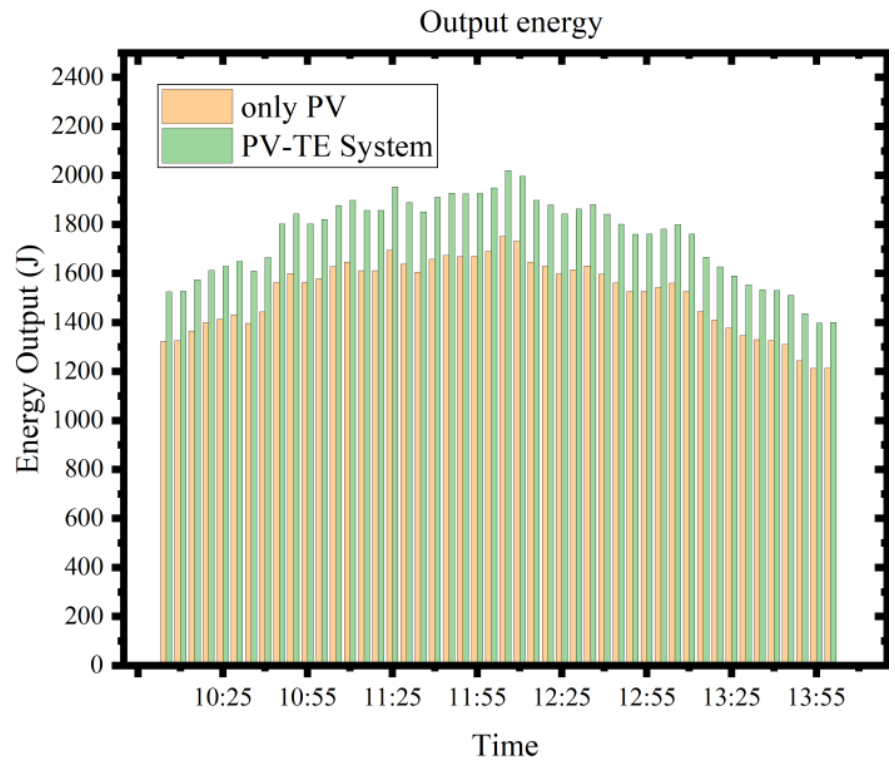

Fig. 13. Comparison of the output power of PV-TE System and only PV

greatly improved, with a maximum increase of $15.65 \%$ in PV-TE system compared with that of a single PV panel without TE device.

In this work, the PV-TE system can work at lower temperature because of the control/monitoring/stabilizing circuits. Some modules can be powered by the electric energy obtained by the thermoelectric conversion principle, and the electric energy output of the whole system can be monitored, so as to realize the effect of waste heat recovery and reuse. Therefore, compared with other work, our efficiency has been significantly improved. Fig. 12 and Table I has quantified the energy efficiency enhancement from the aspects of sunshine efficiency change and energy efficiency improvement. From the perspective of the use of electric energy, the use of any electrical appliance must actually meet its rated voltage in order to make it work normally. Therefore, once the peripheral circuits are removed, the measured output power of the entire system can only be called the "theoretical value" instead of the "actual value". As mentioned in the theoretical part, the electrical energy output of the overall system is related to the size of the load resistance. Although the output power of the entire system can be measured with experimental equipment, there are still certain difficulties in normalizing the comparison. Hence, we prepare to solve this issue by using other methods such as MPPT technique in the future work. 
Table I

Comparison of similar studies

\begin{tabular}{|c|c|c|c|c|c|}
\hline l & $\begin{array}{c}\text { Lamba et al. } \\
{[27]} \\
2016 \\
\end{array}$ & $\begin{array}{l}\text { Li et al. } \\
{[28]} \\
2017 \\
\end{array}$ & $\begin{array}{c}\text { Riahi et al. } \\
{[29]} \\
2020 \\
\end{array}$ & $\begin{array}{c}\text { Yin et al. } \\
{[30]} \\
2019 \\
\end{array}$ & $\begin{array}{c}\text { This work } \\
2021\end{array}$ \\
\hline Energy & & & & & \\
\hline $\begin{array}{l}\text { Conversion } \\
\text { System }\end{array}$ & PV-TE & PV-TE & PV-TE & PV-TE & PV-TE \\
\hline Technology & $\begin{array}{l}\text { Thermodynamic } \\
\text { mode }\end{array}$ & $\begin{array}{l}\text { Hybrid system } \\
\text { exergy } \\
\text { conservation } \\
\text { calculation }\end{array}$ & $\begin{array}{l}\text { Concentrated } \\
\text { photovoltaic thermal } \\
\text { thermoelectric } \\
\text { technology }\end{array}$ & $\begin{array}{l}\text { Optimal load } \\
\text { resistance of the } \\
\text { TE module }\end{array}$ & $\begin{array}{l}\text { Intelligent power } \\
\text { track switching } \\
\text { and efficient } \\
\text { thermal } \\
\text { management }\end{array}$ \\
\hline Analysis Type & $\begin{array}{l}\text { Theoretical model / } \\
\text { Simulation }\end{array}$ & $\begin{array}{l}\text { Theoretical } \\
\text { model / } \\
\text { Simulation }\end{array}$ & Experiment & Experiment & Experiment \\
\hline $\begin{array}{l}\text { Cooling method } \\
\text { Heat utilization }\end{array}$ & $\underset{\times}{\operatorname{heatsink}}$ & $\begin{array}{l}\text { heatsink } \\
\times\end{array}$ & $\underset{\times}{\text { water }}$ & $\begin{array}{c}\text { water } \\
\times\end{array}$ & $\underset{\checkmark}{\text { heatsink }}$ \\
\hline $\begin{array}{c}\text { Stable voltage } \\
\text { design }\end{array}$ & I & 1 & $x$ & $x$ & $\checkmark$ \\
\hline $\begin{array}{l}\text { Control and } \\
\text { Monitor }\end{array}$ & 1 & 1 & $x$ & $x$ & $\checkmark$ \\
\hline $\begin{array}{l}\text { Battery } \\
\text { protection }\end{array}$ & / & I & $x$ & $x$ & $\checkmark$ \\
\hline $\begin{array}{l}\text { Material of PV } \\
\text { panel }\end{array}$ & C-Si & Polymer & Monocrystalline & $\begin{array}{l}\text { 3-junctions } \\
\text { Gallium } \\
\text { Arsenide }\end{array}$ & CIGS \\
\hline $\begin{array}{l}\text { Output Power } \\
\text { Maximum }\end{array}$ & l & l & $1.23 \mathrm{~W}$ & $1.51 \mathrm{~W}$ & $7.02 \mathrm{~W}$ \\
\hline $\begin{array}{c}\text { Energy } \\
\text { Conversion } \\
\text { Efficiency }\end{array}$ & $10.2 \%$ & $8.0 \%$ & $7.27 \%$ & $18.1 \%$ & $21.6 \%$ \\
\hline $\begin{array}{l}\text { Improvement of } \\
\text { Energy } \\
\text { Conversion } \\
\text { Efficiency }\end{array}$ & $13.26 \%$ & $6.6 \%$ & $7.46 \%$ & $8.7 \%$ & $15.65 \%$ \\
\hline
\end{tabular}

\section{CONCLUSION}

In this paper, a PV-TE system using efficient thermal management and an intelligent switching circuit has been designed and validated. In order to further improve the energy efficiency of solar energy, a thermal-management mechanism, incorporating a controlled power-track switching technique, is developed, which can effectively convert thermal energy to electrical energy. With our proposed system, a photovoltaic panel is cooled when harvest energy is obtained. Results show that the PV-TE system can generate an electrical energy of $7.02 \mathrm{~W}$ and achieve a conversion efficiency of $21.6 \%$. Compared with the single photovoltaic cell solution, our proposal showed that a maximum conversion efficiency of up to $15.65 \%$ was achieved with an output power increase of $0.633 \mathrm{~W}$ from $4.03 \mathrm{~W}$ to $4.663 \mathrm{~W}$ in the experiment. The obtained maximum output power can reach $7.02 \mathrm{~W}$ in our proposed system. Moreover, the thermal gradient of photovoltaic cells is indirectly reduced by TEG, since the operating temperature of our work is $11 \%$ lower than that of a single photovoltaic cell system, on average. Our scheme improves energy efficiency using an efficient thermal-management mechanism, readily lending itself to the development of self-powered devices.

\section{REFERENCES}

[1] B. Aksanli and T. S. Rosing. "Human Behavior Aware Energy Management in Residential Cyber-Physical Systems," IEEE Trans. Emerg. Top. Comput., vol. 8, no. 1, pp. 45-57, 2020.

[2] Y. Li, N. Fatima, M. Ahmad, G. Jabeen and X. Li, "Dynamic Long-Run Connections among Renewable Energy Generation, Energy Consumption, Human Capital and Economic Performance in Pakistan," in 2019 4th International Conference on Power and Renewable Energy (ICPRE), Chengdu, China, Sept. 21-23, pp. 152-156, 2019.

[3] D. Gielen, F. Boshell, D. Saygin, M. D. Bazilian, N. Wagner, R. Gorini. "The role of renewable energy in the global energy transformation," Energy Strateg. Rev., vol. 24, pp. 38-50, 2019.

[4] M. Z. Hakuba et al., "Earth's Energy Imbalance Measured From Space," IEEE Trans. Geosci. Remote Sensing, vol. 57, no. 1, pp. 32-45, 2019.

[5] F. Deng, L. Ma, X. Gao and J. Chen. "The MR-CA Models for Analysis of Pollution Sources and Prediction of PM2.5," IEEE Trans. on Systems, Man, and Cybernetics: Systems, vol., no. 4, pp. 814-820, 2019

[6] I. Celik et al., "Energy Payback Time (EPBT) and Energy Return on Energy Invested (EROI) of Perovskite Tandem Photovoltaic Solar Cells," IEEE J. Photovolt, vol. 8, no. 1, pp. 305-309, 2018.

[7] G. Perveen, M. Rizwan and N. Goel. "Comparison of intelligent modelling techniques for forecasting solar energy and its application in solar PV based energy system," IET Energy Systems Integration, vol. 1 , no. 1 , pp. 34-51, 2019.

[8] M. Dhimish and P. Mather. "Development of Novel Solar Cell Micro Crack Detection Technique," IEEE Trans. Semicond. Manuf., vo. 32 , no. 3, pp. 277-285, 2019.

[9] X. Xu, M. M. Meyers, B. G. Sammakia, B. T. Murray and C. Chen, "Performance and Reliability Analysis of Hybrid Concentrating Photovoltaic/Thermal Collectors With Tree-Shaped Channel Nets' 
Cooling System," IEEE Trans. Compon. Pack. Manuf. Technol., vol. 3, no. 6, pp. 967-977, 2013.

[10] R. Subramanian, C. Murugesan, S. Tamilkolundu and D. Jaganath, "Enhancement of wind speed using converging duct for cooling off-grid mast-mounted flat solar PV panels to improve its power generation," IET Renew. Power Gener., vol. 14, no. 2, pp. 263-269, 2020.

[11] P. Saxena and N. E. Gorji. "COMSOL Simulation of Heat Distribution in Perovskite Solar Cells: Coupled Optical-Electrical-Thermal 3-D Analysis," IEEE J. Photovolt., vol.9, no. 6, pp. 1693-1698, 2019.

[12] S. Mehrotra, P. Rawat, M. Debbarma, K. Sudhakar. "Performance of a solar panel with water immersion cooling technique," Int J Sci Environ Technol., vol. 3, pp. 1161-72, 2014.

[13] M. Kuo and W. Lo, "A Combination of Concentrator Photovoltaics and Water Cooling System to Improve Solar Energy Utilization," IEEE Trans. Ind. Appl., vol. 50, no. 4, pp. 2818-2827, 2014.

[14] D. Menka, S. K. Sharma, and R. Saxena. "Solar Power Based PMSM Drive Employed in Refrigeration Plants for Isolated Areas. Industry Applications," IEEE Trans. Ind. Appl., vol. 54, no. 6, pp. 6299-6308, 2018.

[15] T. Cui, Y. Xuan, E.Yin, et al. "Experimental investigation on potential of a concentrated photovoltaic-thermoelectric system with phase change materials," Energy, vol. 122, no.1, pp. 94-102, 2017.

[16] J. Siecker, K. Kusakana, and B. P. Numbi. "A review of solar photovoltaic systems cooling technologies," Renew. Sust. Energ. Rev., vol. 79, pp. 192-203, 2017.

[17] N. Wang et al., "A Double-Voltage-Controlled Effective Thermal Conductivity Model of Graphene for Thermoelectric Cooling," IEEE Trans. Electron Devices., vol. 65, no. 3, pp. 1185-1191, 2018.

[18] C. Jia et al., "Theoretical Analysis of a 750-nm Bandwidth Hollow-Core Ring Photonic Crystal Fiber With a Graded Structure for Transporting 38 Orbital Angular Momentum Modes," IEEE Access, vol. 6, pp. 20291-20297, 2018.

[19] N. Wanget al. "Thermoelectric Parameter Modeling of Single-Layer Graphene Considering Carrier Concentration and Mobility with Temperature and Gate Voltage," IEEE Access, vol. 7, pp. 139329-139336, 2019.

[20] N. Wang, C. Gao, C. Ding, H. Jia, G. Sui and X. Gao. "A Thermal Management System to Reuse Thermal Waste Released by High-Power Light-Emitting Diodes," IEEE Trans. Electron Devices, vol. 66, no. 11, pp. 4790-4797, 2019.

[21] M. Kuo and W. Lo, "A Combination of Concentrator Photovoltaics and Water Cooling System to Improve Solar Energy Utilization," IEEE Trans. Ind. Appl., vol. 50, no. 4, pp. 2818-2827, 2014.

[22] M. N. Ibrahim, H. Rezk, M. Al-Dahifallah and P. Sergeant. "Hybrid Photovoltaic-Thermoelectric Generator Powered Synchronous Reluctance Motor for Pumping Applications," IEEE Access, vol. 7, pp. 146979-146988, 2019.

[23] N. S. Nazri, A. Fudholi, B. Bakhtyar, et al. "Energy economic analysis of photovoltaic-thermal-thermoelectric (PVT-TE) air collectors," Renew. Sust. Energ. Rev., vol. 92, pp. 187-197, 2018.

[24] P. M. Rodrigo, Á. Valera, E. F. Fernández and F. M. Almonacid, "Annual Energy Harvesting of Passively Cooled Hybrid Thermoelectric Generator-Concentrator Photovoltaic Modules," IEEE J. Photovolt., vol. 9, no. 6, pp. 1652-1660, 2019.

[25] J. Yan, X. Liao, S. Ji and S. Zhang, "MEMS-Based Thermoelectric-Photoelectric Integrated Power Generator," $J$. Microelectromech. Syst., vol. 28, no. 1, pp. 1-3, 2019.

[26] W. Gu, T. Ma, Song. A, Ma. Li, Shen, L. "Mathematical modelling and performance evaluation of a hybrid photovoltaic-thermoelectric system," Energy Conv. Manag., vol. 198, 111800, 2019.

[27] R. Lamba, and S. C. Kaushik, "Modeling and performance analysis of a concentrated photovoltaic-thermoelectric hybrid power generation system," Energy Conv. Manag., vol. 115, pp. 288-298, 2016.

[28] D. Li, Y. Xuan, Q. Li, H. Hon, "Exergy and energy analysis of photovoltaic-thermoelectric hybrid systems," Energy, vol. 126, pp. 343-351, 2017.

[29] A. Riahi, M. Balghouthi, et al. "Performance investigation of a concentrating photovoltaic thermal hybrid solar system combined with thermoelectric generators," Energy Conv. Manag., vol. 205, $112377,2020$.
[30] E. Yin, Q. Li, Y. Xuan. "Experimental optimization of operating conditions for concentrating photovoltaic-thermoelectric hybrid system," J. Power Sources, vol. 422, pp. 25-32, 2019.

[31] S. Pal, S. Bose, et al. "A highly stable reliable SRAM cell design for low power applications," Microelectron. Reliab., vol. 105, 113503, 2020.

[32] T. Ngo, A. Huang and Y. Guo, "Analysis and Design of a Reconfigurable Rectifier Circuit for Wireless Power Transfer," IEEE Trans. Ind. Electron., vol. 66, no. 9, pp. 7089-7098, 2019

[33] https://www.ti.com/ INA219.pdf

[34] P. Liu and L. Chien, "A High-Efficiency Integrated Multimode Battery Charger With an Adaptive Supply Voltage Control Scheme," IEEE Trans. Power Electron., vol. 33, no. 8, pp. 6869-6876, 2018. 